\title{
A Note on Projective Klingenberg Planes over Rings of Plural Numbers
}

\author{
Atilla Akpinar, Abdurrahman Dayığlu, İsa Doğan*, Berçem Boztemür*, \\ Derya Aslan*, Zeynep Sena Gürel*
}

\begin{abstract}
This paper deals with a certain class of projective Klingenberg planes over the local ring $F[\eta] /<\eta^{\wedge}\{m\}>$ with $F$ an arbitrary field, known as the plural algebra of order $\mathbf{m}$. In particular addition and multiplication of points on a line is defined geometrically and interpreted algebraically, by using the coordinate ring.
\end{abstract}

Index Terms-plural algebra, local ring, projective Klingenberg plane, geometric addition and multiplication.

\section{INTRODUCTION}

Klingenberg in [13] introduced real plural algebras as an example of an H-ring without using the name "plural numbers". Jukl, in [8], studied the real plural algebra of order $\mathrm{m}$ and investigated linear forms on a free finite dimensional module M, especially their kernel. Jukl continued to study free finite dimensional modules in [9]. In [5], Erdogan et. al. investigated some properties of the modules constructed over the real plural algebra and later, in [6], Ciftci and Erdogan obtained an n- dimensional projective coordinate space associated with the $(n+1)$ - dimensional free module over this real plural algebra. For more detailed information on modules, see [14]. For the algebraic and linear algebraic notions that will be used throughout this paper, we refer to [7] and [15]

In this paper we will study a class of projective Klingenberg $(\mathrm{PK})$ planes coordinatized by the plural algebra (of order m) $\mathbf{A}:=\mathrm{F}+\mathrm{F} \eta+F \eta^{2}+\cdots+F \eta^{\wedge}\{\mathrm{m}-1\}$ such that $\eta^{\wedge}\{\mathrm{m}\}=0$ for $\eta \notin F$ (where $F$ is a field), namely, by the local ring $F[\eta] /<\eta^{\wedge}\{m\}>$. In particular addition and multiplication of points on a line is defined geometrically and interpreted algebraically, by using the coordinate ring. This generalizes a result of Celik and Erdogan [4] for the case of dual numbers $(\mathrm{m}=2)$.

\section{PRELIMINARIES}

In this section we will give some definitions and results which will be the basis of this paper.

A ring $\mathbf{R}$ with identity element 1 is called local if the set $\mathbf{I}$

Atilla Akpınar, University of Uludağ, Faculty of Science and Art, Department of Mathematics, 16059, Bursa, Turkey

Abdurrahman Dayıoğlu, University of Uludağ, Faculty of Science and Art, Department of Mathematics, 16059, Bursa, Turkey

(*) University of Uludağ, Institute of Science, Department of Mathematics, 16059, Bursa, Turkey. of its non-unit elements is an ideal. Then $\mathbf{R} / \mathbf{I}$ is a (skew) field and also either $\mathrm{x}$ or 1-x is a unit.

Let $F$ be a field. Let $\eta^{\wedge}\{m\}=0$ for $\eta \notin F$. Consider $\mathbf{A}:=\mathrm{F}(\eta)=\mathrm{F}+\mathrm{F} \eta+\mathrm{F} \eta^{2}+\cdots+\mathrm{F} \eta^{\wedge}\{\mathrm{m}-1\} \quad$ with componentwise addition and multiplication modulo $\eta^{\wedge}\{\mathrm{m}\}$. Then $\mathbf{A}$ is a (unital, commutative and associative) local ring with the maximal ideal $\mathbf{I}=\mathbf{A} \eta$ of non-units. Also, the local $\operatorname{ring} \mathbf{A}$ can be considered as plural F-algebra of order $m$ with a basis $\left\{1, \eta, \eta^{2}, \cdots, \eta^{\wedge}\{m-1\}\right\}$. Note that the algebra can be seen as quotient ring of the polynomial ring $F[\eta]$ by the principal ideal $<\eta^{\wedge}\{m\}>$. For more detailed information about quotient rings, it can be seen to [16]. If we choose the field of real numbers instead of $F$ then we have the real plural algebra of order m (see [8, Def. 1.1])

It is clear that an element $\mathrm{x}$ of $\mathbf{A}$ is of the form $x=a_{0}+a_{1} \eta+a_{2} \eta^{2}+\cdots+a_{-}\{m-1\} \eta^{\wedge}\{m-1\}$ where $a_{-}\{i\} \in F$ for $0 \leq \mathrm{i} \leq \mathrm{m}-1$.

Now we can consecutively state the following two results, analogues of Proposition 1.3 and 1.5 given in [8], without proof.

\section{Proposition 1.}

An element $x=a_{0}+a_{1} \eta+a_{2} \eta^{2}+\cdots+a_{-}\{m-1\} \eta^{\wedge}\{m-1\} \in \mathbf{A}$ is a unit if and only if $a_{0} \neq 0$.

\section{Proposition 2.}

$\mathbf{A}$ is a local ring with maximal ideal $\eta \mathbf{A}$. The subsets $\eta^{\wedge}\{j\} \mathbf{A}$, $1 \leq \mathrm{j} \leq \mathrm{m}$, are all ideals in $\mathbf{A}$.

From [2] we recall the following:

\section{Definition 3.}

Let $\mathbf{M}=(\mathbf{P}, \mathbf{L}, \in, \sim)$ consist of an incidence structure $(\mathbf{P}, \mathbf{L}, \in)$ (points, lines, incidence) and an equivalence relation ' $\sim$ ' (neighbour relation) on $\mathbf{P}$ and on $\mathbf{L}$. Then $\mathbf{M}$ is called a projective Klingenberg plane (PK-plane), if it satisfies the following axioms:

(PK1) If $\mathrm{P}, \mathrm{Q}$ are non-neighbour points, then there is a unique line $\mathrm{PQ}$ through $\mathrm{P}$ and $\mathrm{Q}$.

(PK2) If $\mathrm{g}, \mathrm{h}$ are non-neighbour lines, then there is a unique point $\mathrm{g} \wedge \mathrm{h}$ on both $\mathrm{g}$ and $\mathrm{h}$.

(PK3) There is a projective plane $\mathbf{M}^{\wedge}\{*\}=\left(\mathbf{P}^{\wedge}\{*\}, \mathbf{L}^{\wedge}\{*\}, \in\right)$ and an incidence structure epimorphism $\Psi: \mathrm{M} \rightarrow \mathrm{M}^{\wedge}\{*\}$, such that the conditions

$$
\Psi(\mathrm{P})=\Psi(\mathrm{Q}) \Leftrightarrow \mathrm{P} \sim \mathrm{Q}, \Psi(\mathrm{g})=\Psi(\mathrm{h}) \Leftrightarrow \mathrm{g} \sim \mathrm{h}
$$

hold for all $\mathrm{P}, \mathrm{Q} \in \mathbf{P}, \mathrm{g}, \mathrm{h} \in \mathbf{L}$.

Let $\mathbf{R}$ be a local ring. Then $\operatorname{M(R})=(\mathbf{P}, \mathbf{L}, \in, \sim)$ is the 
incidence structure with neighbour relation defined as follows:

$\mathbf{P}=\{(\mathrm{x}, \mathrm{y}, 1) \mid \mathrm{x}, \mathrm{y} \in \mathbf{R}\} \cup\{(1, \mathrm{y}, \mathrm{z}) \mid \mathrm{y} \in \mathbf{R}, \mathrm{z} \in \mathbf{I}\} \cup\{(\mathrm{w}, 1, \mathrm{z}) \mid \mathrm{w}, \mathrm{z} \in \mathbf{I}\}$,

$\mathbf{L}=\{[\mathrm{m}, 1, \mathrm{k}] \mid \mathrm{m}, \mathrm{k} \in \mathbf{R}\} \cup\{[1, \mathrm{n}, \mathrm{p}] \mid \mathrm{p} \in \mathbf{R}, \mathrm{n} \in \mathbf{I}\} \cup\{[\mathrm{q}, \mathrm{n}, 1] \mid \mathrm{q}, \mathrm{n} \in \mathbf{I}\}$,

$$
\begin{aligned}
& {[\mathrm{m}, 1, \mathrm{k}]=\{(\mathrm{x}, \mathrm{xm}+\mathrm{k}, 1) \mid \mathrm{x} \in \mathbf{R}\} \cup\{(1, \mathrm{zk}+\mathrm{m}, \mathrm{z}) \mid \mathrm{z} \in \mathbf{I}\}} \\
& {[1, \mathrm{n}, \mathrm{p}]=\{(\mathrm{yn}+\mathrm{p}, \mathrm{y}, 1) \mid \mathrm{y} \in \mathbf{R}\} \cup\{(\mathrm{zp}+\mathrm{n}, 1, \mathrm{z}) \mid \mathrm{z} \in \mathbf{I}\},} \\
& {[\mathrm{q}, \mathrm{n}, 1]=\{(1, \mathrm{y}, \mathrm{yn}+\mathrm{q}) \mid \mathrm{y} \in \mathbf{R}\} \cup\{(\mathrm{w}, 1, \mathrm{wq}+\mathrm{n}) \mid \mathrm{w} \in \mathbf{I}\} .}
\end{aligned}
$$$$
\mathrm{P} \quad=\left(\mathrm{x}_{1}, \mathrm{x}_{2}, \mathrm{x}_{3}\right) \sim\left(\mathrm{y}_{1}, \mathrm{y}_{2}, \mathrm{y}_{3}\right)=\mathrm{Q} \Leftrightarrow
$$$$
\left.x_{-}\{\mathrm{i}\}-y_{-}\{\mathrm{i}\} \in \mathrm{I}(\mathrm{i}=1,2,3)\right), \forall \mathrm{P}, \mathrm{Q} \in \mathbf{P} \text {; }
$$$$
\mathrm{g} \quad=\left[\mathrm{x}_{1}, \mathrm{x}_{2}, \mathrm{x}_{3}\right] \sim\left[\mathrm{y}_{1}, \mathrm{y}_{2}, \mathrm{y}_{3}\right]=\mathrm{h} \Leftrightarrow
$$$$
\left.x_{-}\{i\}-y_{-}\{i\} \in I(i=1,2,3)\right), \forall g, h \in \mathbf{L} \text {. }
$$

From [2] we recall the following theorem.

\section{Theorem 4.}

$\mathbf{M}(\mathbf{R})$ is a PK-plane, and each desarguesian PK-plane is isomorphic to some $\mathrm{M}(\mathbf{R})$.

For more detailed information about desarguesian PK-plane, it can be seen to the papers of $[1,10]$. By Theorem 4 it is obvious that $\mathrm{M}(\mathbf{A})$ is a PK-plane.

An n-tuple $(n \geq 3)$ of pairwise non-neighbour points is called an (ordered) n-gon if no three of its elements are on neighbour lines.

Baker et. al., [2], use $\mathrm{O}=(0,0,1), \mathrm{U}=(1,0,0), \mathrm{V}=(0,1,0)$, $\mathrm{E}=(1,1,1)$ as a coordinatization 4 -gon of a PK-plane.

Finally, we give the definition of addition and multiplication of points on the line OU of $\mathrm{M}(\mathbf{A})$ in the sense of [4].

\section{Definition 5.}

Let $\mathrm{A}$ and $\mathrm{B}$ be non-neighbour points on the line $\mathrm{OU}=[0,1,0]$ of $\mathrm{M}(\mathbf{A})$. Then

i) $\mathrm{A}+\mathrm{B}$ is defined as the intersection point of the lines $\mathrm{LV}$ and $\mathrm{OU}$ where $\mathrm{L}=\mathrm{KU} \wedge \mathrm{BS}, \mathrm{K}=\mathrm{AV} \wedge \mathrm{OS}, \mathrm{S}=(1,1,0)$.

ii) $\mathrm{A} \cdot \mathrm{B}$ is defined as the intersection point of the lines $\mathrm{VN}$ and $\mathrm{OU}$ where $\mathrm{N}=\mathrm{AS} \wedge \mathrm{OM}, \mathrm{M}=\mathrm{BV} \wedge \mathrm{IS}, \mathrm{S}=(1,1,0), \mathrm{I}=(1,0,1)$.

In the next section, we will give the main results.

\section{ThE MAIN RESUlts}

We immediately start with giving the following proposition which is analogue of a result given in [4]. The calculations in the proof of the proposition are based on similar calculations used in the coordinatization procedure for general PK-planes due to Keppens [11, 12].

\section{Proposition 6.}

The addition and multiplication of two non-neighbour points $\mathrm{A}$ and $\mathrm{B}$ on the line $\mathrm{OU}$ in $\mathrm{M}(\mathbf{A})$ as defined geometrically in Definition 5 can be calculated algebraically using the ring operations in the coordinatizing plural F-algebra.

Proof. Let $A=(a, 0,1)$ and $B=(b, 0,1)$ be non-neighbour points on the line $\mathrm{OU}=[0,1,0]$ where $\mathrm{a}=\mathrm{a}_{0}+\mathrm{a}_{1} \eta+\mathrm{a}_{2} \eta^{2}+\cdots+\mathrm{a}_{-}\{\mathrm{m}-1\} \eta^{\wedge}\{\mathrm{m}-1\} \in \mathbf{A}$

and $\mathrm{b}=\mathrm{b}_{0}+\mathrm{b}_{1} \eta+\mathrm{b}_{2} \eta^{2}+\cdots+\mathrm{b}_{-}\{\mathrm{m}-1\} \eta^{\wedge}\{\mathrm{m}-1\} \in \mathbf{A}$.

i) For the lines $\mathrm{AV}=[1,0, \mathrm{a}]$ and $\mathrm{OS}=[1,1,0]$, we have the intersection point as $\mathrm{K}=(\mathrm{a}, \mathrm{a}, 1)$. Also, for the lines $\mathrm{BS}=[1,1,-\mathrm{b}]$ and $\mathrm{KU}=[0,1, \mathrm{a}]$, we get the intersection point as $\mathrm{L}=(\mathrm{a}+\mathrm{b}, \mathrm{a}, 1)$. Finally

$$
\begin{aligned}
\mathrm{A}+\mathrm{B} & =\mathrm{LV} \wedge \mathrm{OU} \\
& =[1,0, \mathrm{a}+\mathrm{b}] \wedge \mathrm{OU} \\
& =(a+b, 0,1)
\end{aligned}
$$

is obtained.

If $\mathrm{B}=(1,0, \mathrm{z})$, that is, $\mathrm{B} \sim \mathrm{U}$, then for the lines $\mathrm{AV}=[1,0, \mathrm{a}]$ and $\mathrm{OS}=[1,1,0]$, we have the intersection point as $\mathrm{K}=(\mathrm{a}, \mathrm{a}, 1)$. Also, for the lines $\mathrm{BS}=[\mathrm{z},-\mathrm{z}, 1]$ and $\mathrm{KU}=[0,1, \mathrm{a}]$ we get the intersection point as $\mathrm{L}=\left(1, \mathrm{z} \cdot(1+\mathrm{a} \cdot \mathrm{z})^{-1} \cdot \mathrm{a}, \mathrm{Z} \cdot(1+\mathrm{a} \cdot \mathrm{z})^{-} \mathbf{1}\right)$. Finally,

$$
\begin{aligned}
\mathrm{A}+\mathrm{B} & =\mathrm{LV} \wedge \mathrm{OU} \\
& =\left[\mathrm{z} \cdot(1+\mathrm{a} \cdot \mathrm{z})^{-1}, 0,1\right] \wedge[0,1,0] \\
& =\left(1,0, \mathrm{z} \cdot\left(1+\mathrm{a} \cdot \mathrm{z}^{-}\right)^{-1}\right) \\
& =\left(1,0, \mathrm{z}^{-}\right)=\mathrm{B}^{-}
\end{aligned}
$$

is obtained.

ii) Since $A, B \nsim O$ we know that $a$ and $b$ are units of $\mathbf{A}$. For the lines $\mathrm{IS}=[1,1,-1]$ and $\mathrm{BV}=[1,0, \mathrm{~b}]$ we have the intersection point as $M=(b, b-1,1)$. Also, for the lines $A S=[1,1,-a]$ and $\mathrm{OM}=\left[1-\mathrm{b}^{-1}, 1,0\right]$ we get the intersection point as $\mathrm{N}=(\mathrm{a} \cdot \mathrm{b},(\mathrm{a} \cdot \mathrm{b})-\mathrm{a}, 1)$. Finally,

$$
\begin{aligned}
\mathrm{A} \cdot \mathrm{B} & =\mathrm{VN} \wedge \mathrm{OU} \\
& =[1,0, \mathrm{a} \cdot \mathrm{b}] \wedge[0,1,0] \\
& =(a \cdot b, 0,1)
\end{aligned}
$$

is obtained.

If $\mathrm{B}=(1,0, \mathrm{z})$, that is, $\mathrm{B} \sim \mathrm{U}$, then for the lines $\mathrm{IS}=[1,1,-1]$ and $\mathrm{BV}=[\mathrm{z}, 0,1]$ we have the intersection point as $\mathrm{M}=(1,1-\mathrm{z}, \mathrm{z})$. Also, for the lines $A S=[1,1,-\mathrm{a}]$ and $\mathrm{OM}=[1-\mathrm{z}, 1,0]$ we get the intersection point as $\mathrm{N}=\left(1,1-\mathrm{z}, \mathrm{z} \cdot \mathrm{a}^{-}{ }^{1}\right)$. Finally,

$$
\begin{aligned}
\mathrm{A} \cdot \mathrm{B} & =\mathrm{VN} \wedge \mathrm{OU} \\
& =\left[{\mathrm{z} \cdot \mathrm{a}^{-}}^{1}, 0,1\right] \wedge[0,1,0] \\
& =\left(1,0, \mathrm{Z}^{-\mathrm{a}^{-}} \mathbf{1}\right) \\
& =\left(1,0, \mathrm{z}^{\prime}\right) \\
& =\mathrm{B}^{-}
\end{aligned}
$$

is obtained.

As a corollary of Proposition 6, we can state the following:

\section{Corollary 7.}

The point $S=(1,1,0)$ in Definition 5 may be replaced by any point $\mathrm{S}$ on $\mathrm{UV}$ with $\mathrm{S} \nsim \mathrm{U}, \mathrm{S} \nsim \mathrm{V}$. Hence, the definition of the addition and multiplication of points on the line OU is independent of the choice of the point $S$.

Proof. If $\mathrm{S}^{-}$is an arbitrary point on the line UV non-neighbour to $\mathrm{V}$ then, let $\mathrm{S}^{-}=(1, \mathrm{~s}, 0)$ 
where $s=s_{0}+s_{1} \eta+s_{2} \eta^{2}+\cdots+s_{-}\{m-1\} \eta^{\wedge}\{m-1\} \in \mathbf{A}$ is a unit since $\mathrm{S}^{-} \nsim \mathrm{U}$. By similar calculations we replace $\mathrm{S}^{-}$by $\mathrm{S}^{-}$in the proof of Proposition 6. Then,

i) For the lines $\mathrm{AV}=[1,0, \mathrm{a}]$ and $\mathrm{OS}^{-}=[\mathrm{s}, 1,0]$ we have the intersection point as $\mathrm{K}=(\mathrm{a}, \mathrm{a} \cdot \mathrm{s}, 1)$. Also, for the lines $\mathrm{BS}$ $=[\mathrm{s}, 1,-(\mathrm{b} \cdot \mathrm{s})]$ and $\mathrm{KU}=[0,1, \mathrm{a} \cdot \mathrm{s}]$, we get the intersection point as $\mathrm{L}=(\mathrm{a}+\mathrm{b}, \mathrm{a} \cdot \mathrm{s}, 1)$. Finally,

$$
\begin{aligned}
\mathrm{A}+\mathrm{B} & =\mathrm{L} V \wedge \mathrm{OU} \\
& =[1,0, \mathrm{a}+\mathrm{b}] \wedge[0,1,0] \\
& =(a+b, 0,1)
\end{aligned}
$$

is obtained.

If $\mathrm{B}=(1,0, \mathrm{z})$, that is, $\mathrm{B} \sim \mathrm{U}$, then for the lines $\mathrm{AV}=[1,0, \mathrm{a}]$ and $\mathrm{OS}^{-}=[\mathrm{s}, 1,0]$, we have the intersection point as $\mathrm{K}=(\mathrm{a}, \mathrm{a} \cdot \mathrm{s}, 1)$. Also, for the lines $\mathrm{BS}{ }^{-}=\left[\mathrm{z},-\left(\mathrm{s}^{-1} \cdot \mathrm{z}\right), 1\right]$ and $\mathrm{KU}=[0,1, \mathrm{a} \cdot \mathrm{s}]$, we get the intersection point as $\mathrm{L}=\left(1, \mathrm{z} \cdot(1+\mathrm{a} \cdot \mathrm{z})^{-1}(\mathrm{a} \cdot \mathrm{s}), \mathrm{z} \cdot(1+\mathrm{a} \cdot \mathrm{z})^{-}{ }^{1}\right)$. Finally,

$$
\begin{aligned}
\mathrm{A}+\mathrm{B} & =\mathrm{LV} \wedge \mathrm{OU} \\
& =\left[\mathrm{z} \cdot(1+\mathrm{a} \cdot \mathrm{z})^{-1}, 1,0,1\right] \wedge[0,1,0] \\
& =\left(1,0, \mathrm{z}^{\prime}(1+\mathrm{a} \cdot \mathrm{z})^{-1}\right) \\
& =\left(1,0, \mathrm{z}^{-}\right) \\
& =\mathrm{B}^{-}
\end{aligned}
$$

is obtained.

ii) For the lines $\mathrm{IS}=[\mathrm{s}, 1,-\mathrm{s}]$ and $\mathrm{BV}=[1,0, \mathrm{~b}]$ we have the intersection point as $\mathrm{M}=(\mathrm{b},(\mathrm{b} \cdot \mathrm{s})-\mathrm{s}, 1)$. Also, for the lines $\mathrm{AS}=[\mathrm{s}, 1,-(\mathrm{a} \cdot \mathrm{s})]$ and $\mathrm{OM}=\left[\mathrm{s}-\left(\mathrm{b}^{-1} \cdot \mathrm{s}\right), 1,0\right]$ where $\mathrm{b} \in \mathbf{A}$ is a unit since $\mathrm{B} \nsim \mathrm{O}$, we get the intersection point as $\mathrm{N}=(\mathrm{a} \cdot \mathrm{b},(\mathrm{a} \cdot \mathrm{b}) \cdot \mathrm{s}-\mathrm{a} \cdot \mathrm{s}, 1)$. Finally

$$
\begin{aligned}
\mathrm{A} \cdot \mathrm{B} & =\mathrm{VN} \wedge \mathrm{OU} \\
& =[1,0, \mathrm{a} \cdot \mathrm{b}] \wedge[0,1,0] \\
& =(a \cdot b, 0,1)
\end{aligned}
$$

is obtained.

If $\mathrm{B}=(1,0, \mathrm{z})$, that is, $\mathrm{B} \sim \mathrm{U}$, then for the lines $\mathrm{IS}=[\mathrm{s}, 1,-\mathrm{s}]$ and $\mathrm{BV}=[\mathrm{z}, 0,1]$, we have the intersection point as $\mathrm{M}=(1, \mathrm{~s}-(\mathrm{z} \cdot \mathrm{s}), \mathrm{z})$. Also for the lines $\mathrm{AS}=[\mathrm{s}, 1,-(\mathrm{a} \cdot \mathrm{s})]$ and $\mathrm{OM}=[\mathrm{s}-(\mathrm{z} \cdot \mathrm{s}), 1,0]$, we get the intersection point as $\mathrm{N}=\left(1, \mathrm{~s}-(\mathrm{z} \cdot \mathrm{s}), \mathrm{z} \cdot \mathrm{a}^{-}{ }^{1}\right)$ where $\mathrm{a} \in \mathbf{A}$ is a unit since $\mathrm{A} \nsim \mathrm{O}$. Finally,

$$
\begin{aligned}
& \mathrm{A} \cdot \mathrm{B}=\mathrm{VN} \wedge \mathrm{OU} \\
& =\left[\mathrm{z} \cdot \mathrm{a}^{-1}, 0,1\right] \wedge[0,1,0] \\
& =\left(1,0, \mathrm{z}^{\circ} \cdot \mathrm{a}^{-1}\right) \\
& =\left(1,0, \mathrm{z}^{-}-\right) \\
& =\mathrm{B}^{-} \text {- }
\end{aligned}
$$

is obtained.

As an immediate consequence of Proposition 6, addition and multiplication of points on the line OU corresponds to addition and multiplication of elements of the local ring $\mathbf{A}$ of plural numbers over a field. This means that $(\mathrm{OU},+, \cdot)$ itself has the structure of a local ring. The situation generalizes the one valid in an ordinary desarguesian (affine or projective) plane over a field $F$ where the points on a line can also be added and multiplicated in such a way that one obtains a field isomorphic to F (see [3, Chapter 3]). Also, in [4], a similar result was obtained for PK-planes over a local ring of dual numbers (over a field or even over a quaternion skewfield).

\section{REFERENCES}

[1] P.Y. Bacon, Desarguesian Klingenberg Planes. Trans. Amer. Math Soc., 241, 1978, 343-355.

[2] C.A. Baker, N.D. Lane, J.W. Lorimer, A coordinatization for Moufang-Klingenberg Planes. Simon Stevin, 65, 1991, 3-22.

[3] M.K. Bennett, Affine and Projective Geometry, New York: Wiley \& Sons Inc., 1995.

[4] B. Celik, F.O. Erdogan, On Addition and Multiplication of points in a certain class of projective Klingenberg planes. Journal of Inequalities and Applications, 230, 1, 2013.

[5] F.O. Erdogan, S. Ciftci, A. Akpınar, On Modules over Local Rings. Analele Univ. "Ovidius" din Constanta, Math Series, 24(1), 2016 217-230.

[6] S. Ciftci, F.O. Erdogan, On projective coordinate spaces. Filomat, 31(4), 2017, 941-952.

[7] T.W. Hungerford, Algebra, New York: Holt, Rinehart and Winston, 1974

[8] M. Jukl, Linear forms on free modules over certain local rings. Acta Univ. Palack. Olomuc. Fac. Rerum Natur. Math., 32, 1993, 49-62.

[9] M. Jukl, Grassmann formula for certain type of modules. Acta Univ. Palack. Olomuc. Fac. Rerum Natur. Math., 34, 1995, 69-74.

[10] M. Jukl, Desargues theorem for Klingenberg projective plane over certain local ring. Acta Univ. Palacki. Olumuc, Mathematica, 36, 1997, 33-39.

[11] D. Keppens, Coordinatization of projective Klingenberg planes, part 2, Simon Stevin, 62, 1988, 163-188.

[12] D. Keppens, Coordinatization of projective Klingenberg planes, part 3, Simon Stevin, 63, 1989, 117-140.

[13] W. Klingenberg, Projektive und affine Ebenen mit Nachbarelementen Math. Z., 60, 1954, 384-406.

[14] B.R. McDonald, Geometric algebra over local rings, New York: Marcel Dekker, 1976.

[15] K. Nomizu, Fundamentals of Linear Algebra, New York: McGraw-Hill., 1966.

[16] J. Rotman, Galois Theory, New York: Springer, 1998. 